\title{
A planetary health approach to secure, safe, sustainable food systems: workshop report
}

\author{
Robyn G. Alders $^{1,2}$ (D) Natalie Ratanawongprasat ${ }^{1,2} \cdot$ Hettie Schönfeldt $^{3} \cdot$ Darryl Stellmach $^{1,2}$
}

Received: 14 September 2017 / Accepted: 20 February 2018 / Published online: 27 March 2018

(C) The Author(s) 2018

\section{Introduction}

Experts from 17 countries across six continents representing practitioners, researchers, policy makers and community development workers (Table 1) gathered from 30 November to 2 December 2016 at the University of Sydney to communicate priority areas in nutritional and environmental health for current food systems. The meeting was hosted by the Charles Perkins Centre and Marie Bashir Institute Healthy Food Systems: Nutrition $\bullet$ Diversity $\bullet$ Safety Node.

The workshop statement below was written for the audience of the $4^{\text {th }}$ International One Health Congress and $6^{\text {th }}$ Biennial Congress of the International Association for Ecology and Health as well as responsible people at all levels. The statement sits within a Planetary Health framework (Whitmee et al. 2015), recognizing that agricultural practices and food systems have contributed to global environmental problems that have profound implications for our health and that of future generations. Regenerative agriculture and food systems designed to efficiently meet optimal human and domestic animal dietary requirements are essential to reversing current unsustainable trends.

Robyn G. Alders

robyn.alders@sydney.edu.au

1 University of Sydney, School of Veterinary Science and School of Life and Environmental Sciences, Camperdown, Australia

2 Charles Perkins Centre and Marie Bashir Institute Healthy Food Systems: Nutrition $\bullet$ Diversity $\bullet$ Safety Node, University of Sydney, Camperdown, Australia

3 Department of Animal and Wildlife Sciences, University of Pretoria, Pretoria, South Africa

\section{Workshop program}

On the first day, participants shared their backgrounds and related research activities that spanned much of the globe. We conducted an engaging visioning exercise in groups, sketching food systems in specific locations in low-, middle- and high-income countries in 1950, 2000 and 2050 that demonstrated how quickly our food systems have changed over time and the potential for significant positive change in the near future. Participants spoke to their discussion papers chosen to reflect disciplinary and geographical diversity:

- 'Agrobiodiversity for healthy, diverse diets and food systems' by Danny Hunter;

- 'Antibiotic usage in chicken production in India' by Jaswinder Singh;

- 'Food systems in the Philippines' by Romeo Gundran;

- 'Food systems in Viet Nam' by Hung Nguyen-Viet;

- 'Gender and nutrition-sensitive agriculture' by Brigitte Bagnol;

- 'People and Agrifood Systems' by Jonathan Rushton;

- 'South African food systems' by Hester Schönfeldt; and

- 'What makes food safe?' by Robyn Alders.

Over the following two days, participants worked in groups to address nominated priority areas through three proposals for collaborative research: 1. 'Food systems and antimicrobial resistance', 2. 'Connecting children to grow food literacy globally', and 3. 'Revisiting sustainable, secure, safe and ethical food systems through a planetary health lens'. Plenary sessions were used to develop a workshop statement and declaration. 
Table 1 Participants in the secure, safe, sustainable food systems workshop held at the University of Sydney in December 2016

\begin{tabular}{|c|c|c|}
\hline Country & Affiliation & Name \\
\hline \multirow[t]{4}{*}{ Australia } & Healthy Food Systems Node, University of Sydney & $\begin{array}{l}\text { Robyn Alders } \\
\text { Brigitte Bagnol } \\
\text { Margaret Allman-Farinelli } \\
\text { Julia de Bruyn } \\
\text { Tim Gill } \\
\text { Kim Heasman } \\
\text { Fiona O'Leary } \\
\text { Natalie Ratanawongprasat } \\
\text { Darryl Stellmach } \\
\text { Stewart Sutherland } \\
\text { Johanna T. Wong }\end{array}$ \\
\hline & Murdoch University, Perth & Mieghan Bruce \\
\hline & Primary Industries and Regions Department, South Australia & Emma Rooke \\
\hline & Save the Children, Sydney & Kavitha Suthanthiraraj \\
\hline Canada & University of Manitoba, Winnipeg & Tim Stevenson \\
\hline India & Guru Angad Dev Veterinary and Animal Sciences University, Ludhiana & Jaswinder Singh \\
\hline Indonesia & University of Indonesia, Jakarta & Wiku B. Adisamito \\
\hline Italy & Bioversity International, Rome & Danny Hunter* \\
\hline Kenya & University of Nairobi, Nairobi & Eric Mitema \\
\hline Mozambique & Universidade Eduardo Mondlane, Maputo & Cristiano Macuamule \\
\hline Nigeria & Green Generation, Lagos & Chinyere Onyia \\
\hline Philippines & Central Luzon State University, Science City of Muñoz & Romeo Gundran \\
\hline South Africa & University of Pretoria, Pretoria & $\begin{array}{l}\text { Mavis Mulaudzi } \\
\text { Hettie Schönfeldt }\end{array}$ \\
\hline Tanzania & Tanzania Veterinary Laboratory Agency, Dar es Salaam & Wende Maulaga \\
\hline & Sokoine University of Agriculture, Morogoro & John Msuya \\
\hline Timor-Leste & Ministry of Agriculture and Fisheries, Dili & $\begin{array}{l}\text { Joanita Jong } \\
\text { Antonino do Karmo }\end{array}$ \\
\hline United Arab Emirates & Dubai Food Control Authority, Dubai & Sayed E.S. Alhashimi \\
\hline United Kingdom & $\begin{array}{l}\text { Liverpool University, Liverpool } \\
\text { Royal Veterinary College, London }\end{array}$ & $\begin{array}{l}\text { Jonathan Rushton* } \\
\text { Richard Kock* }\end{array}$ \\
\hline United States & $\begin{array}{l}\text { Land O'Lakes, Washington DC } \\
\text { Planetary Health Alliance, Harvard University } \\
\text { University of California, Davis }\end{array}$ & $\begin{array}{l}\text { Jennifer Lane } \\
\text { Amalia Almada } \\
\text { Rodrigo A. Gallardo } \\
\text { Huaijun Zhou }\end{array}$ \\
\hline Viet Nam & Hanoi School of Public Health, Hanoi, Viet Nam; International Livestock Research Institute, Hanoi & Hung Nguyen-Viet \\
\hline Zambia & $\begin{array}{l}\text { Ministry of Fisheries and Livestock, Lusaka } \\
\text { National Food and Nutrition Commission, Lusaka }\end{array}$ & $\begin{array}{l}\text { Hilda Lumbwe } \\
\text { Chisela Kaliwale }\end{array}$ \\
\hline
\end{tabular}

*Also a member of Healthy Food Systems Node, University of Sydney

\section{Key points emanating from workshop discussions}

Current food systems are not sustainable, and fail to provide nutritious and safe food (as well as water) to support good health for all.

Agricultural systems have never been explicitly designed to promote human health and, instead, mostly focus on increased profitability for farmers and agricultural industries (Bouis and Welch 2010). This has consequently led to the simplification of the diets of large numbers of people focusing primarily on three staple crops: rice (Oryza sativa L.), wheat (Triticum aestivum L.) and maize (Zea mays L.), as well as a rapid rise in micronutrient malnutrition in many nations (Welch and Graham 1999; Johns 2003). For several decades, the amount of energy in the food supply has increased and inexpensive, processed, energydense foods have become widely marketed and available, potentially playing a role in the rising levels of noncommunicable diseases, overweight and obesity
(Drewnowski and Darmon 2005). Changes in food habits around the world are creating populations whose health status will place unprecedented burdens on health systems. With its focus on the quantity of production, often to the exclusion of other goals, today's food system is on an unsustainable course. Finding solutions requires a deeper understanding of pressures, drivers and threats to create a sustainable food system.

We seek consensus on the transformation of food systems to address current challenges, to ensure good health for our planet, animals and humanity.

It is estimated that current agricultural systems and practices contribute to $24 \%$ of global greenhouse gas emissions (IPCC 2014) and account for around $70 \%$ of freshwater use (FAO 2016), as well as having implications for land use and catastrophic impacts on ecosystems function and biodiversity. Such environmental externalities of food systems generate negative feedbacks, which contribute to the persistence of malnutrition. 
In recent years, food value chains in low- and middleincome countries have undergone rapid transformations. Only a few decades ago most crops (e.g. maize and soya) were grown on family farms interspersed with other small grains (e.g. oats and barley), hay and pasture. These were intended for local or domestic consumption. Food was also purchased at small local markets. The farming family lived on the farm and performed most of the labor themselves, with little or no hired help or specialized machinery. They were an integral part of the agro-ecosystem (Wallinga 2009). Today, most food purchased by consumers has travelled longer distances and has touched several different actors across a food value chain. Industrialization has transformed agriculture from a local, smaller-scale enterprise where most of the needs of the farm were met by on-farm resources into a much more specialized enterprise, where off-farm resources such as fossil fuel energy, pesticides and fertilizers are used intensively (Wallinga 2009). Industrialized and specialized agriculture all impact on human and ecosystem health. A majority of farms now produce just one or two commodities or just one species of animal, and increasingly one age range for that animal. Crop production and animal production have been 'delinked'. Animals once provided cheap horsepower for crop production, and animal manure plus crop refuse in turn were recycled to restore organic matter and fertility into soil as part of the food system. Soils high in organic content can sequester more carbon, better resist erosion and help retain more rainwater, making them more resilient during drought. Manure cannot be economically transported and intensive animal production facilities often lack the associated cropland to spread manure as fertilizer; it is therefore often disposed of in ways leading to nutrient runoff and pollution of surface and/or groundwater resources. Thus, concentrated sources of nutrients are not recycled to the distant soils from which they are drawn, and their accumulation in new locations negatively impacts environmental health.

Food production and the food system are important not only for ensuring that sufficient nutritious and safe food is available to protect against malnutrition and noncommunicable diseases; but also constitute a major environmental responsibility to achieve planetary health (Alders et al. 2016).

We must work together as a global society to change our food systems to produce ethical, accessible, safe and nutritious food for all.

The world's population has been rapidly growing over the past decades. It is expected to reach 8.6 billion in
2030 and 9.8 billion in 2050 (UNDESA 2017). Consequently, food systems face massive challenges to globally produce accessible and nutritious food for all. Since the development of agriculture in the Neolithic Period, egalitarianism and relatively equal accumulation of resources have diminished for most people (Kohn 2017). The food system includes all processes needed to feed people: growing, harvesting, processing, packaging, transporting, marketing, consuming and disposing of food. The food system also involves and is influenced by human resources and social, political, economic and environmental factors (Pinard et al. 2013). The interdependence between the social, economic and environmental agendas is already being recognized at the highest levels and adopted in defining the new set of the world's Sustainable Development Goals.

Collaboration is necessary and requires interdisciplinary perspectives, but is intrinsically difficult, and limitations of conventional collaboration (and the narrow conditions under which it is applicable) continue to exist. Although the end result may be the same ('food security for all'), effective collaboration would essentially require 'stretching' from the usual to ensure equitable participation and distribution across food systems. This includes embracing conflict between the chain of actors, building connections between unlikely allies, experimenting with the way forward and stepping into the game.

The responsibility of achieving balanced food systems lies with individuals and representative bodies of our societies.

The world's biodiversity is declining at an alarming rate. Population sizes of vertebrate species measured by the Living Planet Index (LPI) have more than halved in just over 40 years. The LPI, which measures trends in thousands of populations of mammals, birds, reptiles, amphibians and fish across the globe shows a decline of 58 per cent between 1970 and 2012. If current trends continue, the decline could reach two-thirds by 2020 . The main threats to these populations are habitat loss and degradation, for example conversion of natural areas for agricultural expansion, followed by overexploitation of species, such as unsustainable fishing (WWF 2016).

Destruction of these ecosystems represents a risk not just to plants and wildlife, but to humans as well. Ecosystems provide us with food, fresh water, clean air, energy, medicine and recreation. Given the current unacceptable state of affairs, there is a clear challenge for humanity to learn how to operate within the environmental limits of our planet and to maintain or restore resilience of ecosystems. 


\section{Workshop statement}

We believe that the provision of food for humanity, while ensuring there is sufficient food to maintain biological diversity and support ecosystems, is among the most important and complex of human responsibilities. Our current food systems have met many of the challenges of previous centuries, but have done so with increasing negative consequences. A disconnect between food systems and human needs has both failed to eliminate undernutrition and resulted in epidemics of overnutrition and related non-communicable diseases. Locally and globally, food systems lack resilience in the face of environmental change and market fluctuations. They have become vulnerable to the effects of disease and climatic events. Corporate food systems reduce food to a commodity, eroding our social and cultural relationships to the food we eat. Inappropriate production impacts ecosystems (including soil, water, animals and plants) and generates excessive waste. Our contemporary food systems have created staggering human, financial and environmental costs, while support for the kind of research and development essential to overcoming the inadequacies of the current systems has declined markedly. This necessitates a realignment of food systems, in order to provide sufficient, safe and sovereign food within planetary boundaries.

A food system that ensures optimal health and wellbeing for our planet is possible. An integrated approach-one that involves the whole of society-can provide effective and equitable solutions to our contemporary challenges. The dual burden of under- and overnutrition can be addressed by context-specific nutrition and gender-sensitive approaches to sustainable food systems. Holistic approaches are key to addressing human and environmental risks associated with food supply. Practical interventions must be underpinned by interdisciplinary research and planning around all aspects of food and nutrition security, from soil health, water availability, food production and processing (and their externalities, e.g. plastics) to market chains, consumers and their health and safety, food wastage, and sociocultural issues: a Planetary Health approach to the production of sustainable, nutritious, safe and ethical food, delivered to all with minimal waste, will promote human, animal and environmental wellbeing.

\section{Workshop declaration}

We call upon municipal, national and regional governments, the United Nations and international agencies, corporations, landholders, business people, community organizations and all citizens to recognize and act upon these facts:

- That access to diverse nutritious food and potable water is a right for all life;

- That consumption is exceeding the planet's bio-capacity, thus nutritional inadequacies are related to global resource decline which affects species survival, including the human species;

- That gender, race/colour/ethnicity, poverty, markets, production disparity and forced displacement are key factors that limit access to resources and possibilities to achieve optimal nutrition and wellbeing;

- That agricultural, health, environmental and socioeconomic policies need to be integrated, recognizing that balanced food is essential to good physical, mental and cultural health;

- That food production policies need to account for both quality and quantity - society needs to recognize and value the true cost and benefit of quality food;

- That agricultural frameworks, including subsidies and trade agreements, must support the production, distribution and marketing of food that promotes good health, and account for the external costs to communities, public health, the global economy and the planetary ecosystem;

- That transparency, accountability, traceability and proportionality are essential to make decisions that support sustainability;

- That recompense for inputs at all stages of the value chain must be adequate;

- That regulatory frameworks need to align equity, safety, nutrition and ecology;

- That agriculture-related pests, diseases, invasive species and anti-microbial resistance represent key threats to human and animal health that must be urgently addressed;

- That financial and social support structures should be reoriented to recognize and support the role of women in ensuring nutritional wellbeing in their communities;

- That people across the life cycle, including pregnant and lactating women, children, adolescents and the elderly, in particular, have specific nutritional needs that must be met;

- That all jurisdictions must understand the key importance of water in sustaining life and negotiate fair use for all stakeholders across the full breadth of the waterscape;

- That we need to reverse the loss of soil and its health;

- That the specific food systems and dietary preferences of local communities should be protected, while supporting the reality and potential benefit of globalization and global trade; and

- That policies recognize and extend the appropriate allocation of land and its tenure to enable sustainable and diverse agricultural production. 


\section{Conclusions and way forward}

Access to diverse nutritious food and potable water is a right for all life. Our current food systems supporting humans, domestic animals and plants are neither sustainable nor ecologically sound. An integrated and holistic approach involving the whole of society is needed to reverse unsustainable trends within current food systems. Through linkages established and strengthened during this workshop, we seek to contribute to global discussions, research and outcomes in this area. The Planetary Health community, bringing with it an interdisciplinary and multi-sectoral approach, provides an essential foundation on which strategic pro-nutrition and proenvironmental food systems can be anchored.

Acknowledgements Financial support from the Australia Awards Fellowship Scheme (Grant Agreement R161120) to support the participation of 15 of the workshop participants from Africa and Asia is gratefully acknowledged. Logistical and administrative support provided by the Charles Perkins Centre and the Marie Bashir Institute of the University of Sydney was vital to the success of the workshop.

\section{Compliance with ethical standards}

Conflict of interest The authors declared that they have no conflict of interest.

Open Access This article is distributed under the terms of the Creative Commons Attribution 4.0 International License (http:// creativecommons.org/licenses/by/4.0/), which permits unrestricted use, distribution, and reproduction in any medium, provided you give appropriate credit to the original author(s) and the source, provide a link to the Creative Commons license, and indicate if changes were made.

\section{References}

Alders, R., Nunn, M., Bagnol, B., Cribb, J., Kock, R., \& Rushton, J. (2016). Chapter 3.1 approaches to fixing broken food systems. In M. Eggersdorfer, K. Kraemer, J. B. Cordaro, J. Fanzo, M. Gibney, E. Kennedy, A. Labrique, \& J. Steffen (Eds.), Good nutrition: Perspectives for the 21st century (pp. 132-144). Basel: Karger.
Bouis, H. E., \& Welch, R. M. (2010). Biofortification-A Sustainable Agricultural Strategy for Reducing Micronutrient Malnutrition in the Global South. Crop Science, 50(March-April), S20-S32.

Drewnowski, A., \& Darmon, N. (2005). The economics of obesity: dietary energy and energy cost. American Journal of Clinical Nutrition, 82(Supplement), 265-273.

FAO. (2016). AQUASTAT-water uses. Food and agricultural Orginization of the United Nations. [Online] Available at: http:// www.fao.org/nr/water/aquastat/water_use/index.stm. Accessed 7 July 2017.

IPCC. (2014). Climate change 2014: Sythesis report. Contribution of working groups I, II and III to the fifth assessment report of the intergovernmental panel on climate change, Geneva: IPCC.

Johns, T. (2003). Plant biodiversity and malnutrition: Simple solutions to complex problems. African Journal of Food, Agriculture, Nutrition and Development, 3(1), 45-52.

Kohn, L. (2017). Pristine affluence: Daoist roots in the stone age. St. Petersburg: Three Pines Press.

Pinard, C. A., Kim, S. A., Story, M., \& Yaroch, A. L. (2013). The food and water system: Impacts on obesity. Journal of Law, Medicine and Ethics, Volume, 41, 52-60.

UNDESA. (2017). World population prospects: The 2017 revision, key findings and advance tables. ESA/P/WP/248, New York: United Nations Department of economic and social affairs, Population Division.

Wallinga, D. (2009). Today's food system: How healthy is it? Journal of Hunger and Environmental Nutrition, 4, 251-281.

Welch, R. M., \& Graham, R. D. (1999). A new paradigm for world agriculture: Meeting human needs. - Productive, sustainable, nutritious. Field Crops, Volume, 60, 1-10.

Whitmee, S., Haines, A., Beyrer, C., Boltz, F., Capon, A., Ferreira de Souza Silva, B., Ezeh, A., Frumkin, H., Gong, P., Head, P., Horton, R., Mace, G. M., Marten, R., Myers, S. S., Nishtar, S., Osofsky, S., Pattanayak, S. K., Pongsiri, M. J., Romanellia, C., Soucat, A., Vega, J., \& Yash, D. (2015). Safeguarding human health in the Anthropocene epoch: Report of the Rockefeller Foundationlancet commission on planetary health. The Lancet, 386, 10007 Available: http://www.thelancet.com/pdfs/journals/lancet/ PIIS0140-6736(15)60901-1.pdf.

WWF. (2016). Living planet report 2016: Summary. Switzerland: World Wide Fund. 